\title{
ETIOLOGÍA DE LA MARCHITEZ DEL 'CHILE DE AGUA' (Capsicum annuum L.) EN OAXACA, MÉXICO
}

\section{ETIOLOGY OF PEPPER WILT DISEASE OF 'CHILE DE AGUA' (Capsicum annuum L.) IN OAXACA, MÉXICO}

\author{
Alfonso Vásquez López ${ }^{1 *}$, Bertha Tlapal Bolaños ${ }^{2}$, M. de Jesús Yáñez Morales ${ }^{3}$, Rafael Pérez Pacheco ${ }^{1}$ y \\ Manuel Quintos Escalante ${ }^{4}$
}

\begin{abstract}
${ }^{1}$ Centro Interdisciplinario de Investigación para el Desarrollo Integral Regional, Unidad Oaxaca, Instituto Politécnico Nacional. Calle Hornos 1003. 71230, Santa Cruz Xoxocotlán, Oax. Tel. 01 (951) 5170610 ext. 82736. ${ }^{2}$ Departamento de Parasitología Agrícola, Universidad Autónoma Chapingo. Km. 38.5 Carr. México-Texcoco. 56230, Chapingo, Edo. de México. ${ }^{3}$ Instituto de Fitosanidad, Colegio de Postgraduados. Km. 36.5 Carr. México-Texcoco. 56230, Montecillo, Texcoco, Edo. de México. ${ }^{4}$ Centro Interdisciplinario de Investigación para el Desarrollo Integral Regional, Unidad Durango, Instituto Politécnico Nacional. Sigma s/n, Fracc. 20 de Noviembre II. 34220, Durango, Dgo.
\end{abstract}

* Autor para correspondencia (bremia43@gmail.com)

\section{RESUMEN}

Se determinaron los agentes causales de la marchitez de plantas de 'Chile de agua' (Capsicum annuum L.) en Cuilapam de Guerrero, San Jerónimo Tlacochahuaya y San Sebastián Abasolo, Oaxaca, México. Se colectaron 120 plantas con síntomas de marchitez y se obtuvieron 95 aislamientos fungosos pertenecientes a los géneros: Alternaria, Fusarium, Macrophomina, Rhizoctonia, y Stemphylium, los cuales se aislaron de $15,19,6,38$ y 17 muestras, respectivamente. Además se obtuvieron ocho y siete aislamientos de los oomicetes Phytophthora y Pythium, respectivamente. Los postulados de Koch se cumplieron in vitro e invernadero. En plántulas de $5 \mathrm{~d}$ de edad in vitro, Fusarium lateritium, $F$. oxysporum, Macrophomina sp., Phytophthora capsici, Pythium sp., Rhizoctonia sp. (binucleada) y $\boldsymbol{R}$. solani causaron estrangulamiento y necrosis del cuello de la raíz (ahogamiento) y muerte de plántulas. En plantas de 45 d de edad inoculadas en invernadero los aislamientos patogénicos fueron $P$. capsici y $R$. solani. $P$. capsici causó marchitez, necrosis de cuello de raíz y tallo sin desprendimiento de epidermis y muerte de planta a $6 \mathrm{~d}$ después de la inoculación (ddi). $R$. solani causó marchitez con recuperación temporal de turgencia, necrosis de cuello de raíz y tallo con desprendimiento de epidermis y estrangulamiento de raíces secundarias a $34 \mathrm{ddi}$.

Palabras clave: Capsicum annuum, Phytophthora capsici, Rhizoctonia spp, incidencia, intensidad de enfermedad.

\section{SUMMARY}

The causal agents of wilting disease in 'Chile de agua' plants (Capsicum annuum L.) were determined in Cuilapam de Guerrero, San Jerónimo Tlacochahuaya and San Sebastián Abasolo, Oaxaca, México. One hundred and twenty symptomatic plants were collected in the field from which 95 fungal isolates belonging to the genera: Alternaria, Fusarium, Macrophomina, Rhizoctonia, and Stemphylium, were obtained from 15, 19, 6, 38 and 17 samples, respectively. Also eight isolates of Phytophthora and seven of Pythium were obtained.
Koch postulates were completed in vitro and under greenhouse conditions. In 5 days old seedlings inoculated in vitro, Fusarium lateritium, F. oxysporum, Macrophomina sp., Phytophthora capsici, Pythium sp., Rhizoctonia sp. (binucleate), and $R$. solani caused girdling and neck necrosis of roots (damping off) and death. In 45 days old plants inoculated under greenhouse conditions, the pathogenic isolates were $P$. capsici and $R$. solani. $P$. capsici caused wilting, neck necrosis of roots and stems without peeling of epidermis, and plant death 6 days after inoculation (dai). $R$. solani caused wilting with tempory recovery of turgescence, neck necrosis of roots and stems whit peeling of epidermis and girdling of secondary roots 30 dai.

Index words: Capsicum annuum, Phytophthora capsici, Rhizoctonia spp, incidence, disease intensity.

\section{INTRODUCCIÓN}

En la región "Valles Centrales" del Estado de Oaxaca, México, el cultivo de chile (Capsicum annuum L.) conocido regionalmente como 'Chile de agua', dinamiza la economía local ya que $90 \%$ de la población tiene a esta hortaliza como cultivo primario, porque genera ingresos importantes durante los meses de marzo a agosto; además, durante el proceso de producción se emplean aproximadamente 150 jornales/ha y la relación beneficiocosto del cultivo llega a ser de 3:1 (Velasco et al., 1998).

La producción se destina principalmente a los mercados de la capital oaxaqueña donde se comercializa en fresco como ingrediente importante en la gastronomía regional. En el ciclo agrícola 2002 se sembraron 456 ha con chile de agua en más de 20 localidades de la región, y se 
produjeron 2638 t (INEGI, 2001). En la zona productora los problemas fitosanitarios y agronómicos reducen de manera importante la productividad y calidad del chile. En los ciclos agrícolas 2000 y 2001 la enfermedad conocida como marchitez del chile se presentó con una incidencia que fluctúo entre 60 y $70 \%$ y causó pérdidas económicas significativas a los productores. La enfermedad se observó en plantas de 50 a 60 d de edad y se caracterizó por la marchitez de follaje, caída de flores y frutos, necrosis del tejido externo e interno del cuello de la raíz y muerte de plantas.

A nivel mundial se considera que la marchitez del chile es causada principalmente por Phytophthora capsici Leo. (Galindo, 1962; Bosland y Votava, 2000), pero también hay otros patógenos involucrados: los hongos Rhizoctonia solani (Romero, 1994; Pomar et al., 2001), Fusarium oxysporum Schlechtend. (Black et al., 1993), Verticillium spp. (Nuez et al., 1996; Agrios, 2001), y la bacteria Ralstonia solanacearum (Smith) Yabuuchi et al. comb. nov. (Nuez et al., 1996; Bosland y Votava, 2000). Antes de este estudio, en la región "Valles Centrales" de Oaxaca no se había estudiado con precisión la etiología de esta enfermedad en el cultivo del chile de agua.

En un estudio preliminar realizado por Alfonso Vásquez López en el año 2000 (datos no publicados) se encontró que Phytophthora sp., Pythium sp., y Rhizoctonia sp., son habitantes naturales de la rizosfera de las plantas de chile de agua en las zonas de estudio, pero no se habían completado los postulados de Koch (Agrios, 2001) para verificar su capacidad patogénica. En este trabajo se postula que Phytophthora sp. es el único oomicete que induce marchitez y muerte de estas plantas. El objetivo de este estudio fue determinar la etiología de la marchitez del chile de agua en tres localidades de la región "Valles Centrales" de Oaxaca, México.

\section{MATERIALES Y MÉTODOS}

\section{Muestreo de campo}

En mayo de 2001 y abril de 2002 se colectó un total de 120 plantas de chile de agua con síntomas de marchitez en tres localidades: Cuilapam de Guerrero, San Jerónimo Tlacochahuaya y San Sebastián Abasolo, todas del Estado de Oaxaca. Por localidad y fecha de muestreo se colectaron 20 plantas sintomáticas, donde el patrón de muestreo que se usó fue en "W" (Zadoks y Schein, 1979) en un área de $400 \mathrm{~m}^{2}$ ubicada en el centro de las parcelas muestreadas.

\section{Aislamiento y purificación de hongos y estraminipilas}

De cada planta recolectada en mayo de 2001 se cortaron 10 puntas de raíz de $1.0 \mathrm{~cm}$ de longitud y 10 trozos de tallos de $0.5 \mathrm{~cm}^{3}$; en total se obtuvieron 600 puntas de raíz y 600 trozos de tallo. Estos tejidos se lavaron con agua durante $30 \mathrm{~min}$, se desinfestaron con hipoclorito de sodio a $1 \%$ por $3 \mathrm{~min}$, se lavaron tres veces con agua destilada estéril y secaron en toallas de papel estériles. Las 300 puntas de raíz y los 300 trozos de tallos se sembraron en medio de cultivo PDA ( $200 \mathrm{~g}$ de papa + $12 \mathrm{~g}$ de dextrosa $+18 \mathrm{~g}$ de agar-agar/1.0 $\mathrm{L}$ de agua destilada) y se incubaron a $25{ }^{\circ} \mathrm{C}$ con luz blanca por $5 \mathrm{~d}$. La misma cantidad de tejido se sembró en medio de cultivo 3P (20 g de harina de maíz, $18 \mathrm{~g}$ de agar-agar, $0.8 \mathrm{~mL}$ de pimaricina, $0.02 \mathrm{~g}$ de rifamicina y $0.25 \mathrm{~g} \mathrm{~L}^{-1}$ de ampicilina, en agua destilada) y se incubó a $28^{\circ} \mathrm{C}$ en oscuridad. Las colonias de hongos y estraminipilas formadas se transfirieron a PDA y se incubaron a $25{ }^{\circ} \mathrm{C}$ con luz blanca por $10 \mathrm{~d}$. Los aislamientos se purificaron mediante cultivos monoconidiales o por punta de hifa. Las colonias se preservaron en tubos con PDA cubiertos con aceite mineral estéril. La misma metodología se siguió para procesar las plantas recolectadas en abril de 2002.

\section{Pruebas de patogenicidad in vitro}

Cada aislamiento obtenido en campo se consideró como un tratamiento, cada uno con 25 repeticiones y la unidad experimental fue una plántula de chile de $5 \mathrm{~d}$ de edad. Los aislamientos se cultivaron por $5 \mathrm{~d}$ en cajas de Petri con PDA; posteriormente, las colonias se cubrieron con una capa de suelo estéril (70 \% de arena y $30 \%$ de suelo agrícola) de $0.5 \mathrm{~cm}$ de espesor, y por tratamiento se sembraron 25 plántulas sanas de chile. Las plántulas testigo se sembraron en cajas de Petri con PDA y suelo estéril. Las plántulas sanas se produjeron a partir de semilla desinfestada con hipoclorito de sodio a $1 \%$ por 3 min, se lavaron tres veces con agua destilada estéril y se incubaron en agua-agar $\left(18 \mathrm{~g} \mathrm{~L}^{-1}\right.$ de agar-agar en agua destilada) a $28{ }^{\circ} \mathrm{C}$ en oscuridad. Las plántulas inoculadas y testigos se mantuvieron a temperatura ambiente $(22 \pm 2$ ${ }^{\circ} \mathrm{C}$ ) por $6 \mathrm{~d}$. La incidencia $(\%)$ de plántulas enfermas por tratamiento se evaluó cada $12 \mathrm{~h}$ durante $6 \mathrm{~d}$ y se estimó con la ecuación: $\mathrm{I} i=\Sigma(\mathrm{n} i / \mathrm{N} i) 100$; donde: $\mathrm{I} i=$ incidencia de plántulas enfermas en el momento $i$; $i=$ número de plántulas enfermas en el momento $i ; \mathrm{N} i=$ población total de plántulas inoculadas. La intensidad de enfermedad para cada tratamiento se estimó como el área bajo la curva del progreso de la enfermedad (ABCPE) por el método de integración trapezoidal, mediante la ecuación: 


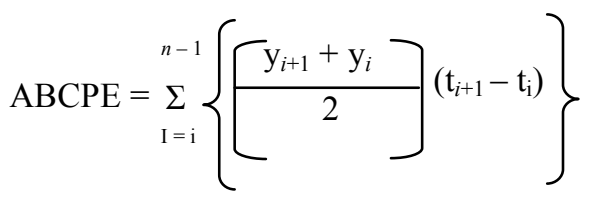

donde: $n=$ número de evaluaciones; $\mathrm{t}_{i+1}=$ tiempo de evaluación (h); $\mathrm{t}_{i}=$ tiempo de evaluación (h) inmediatamente anterior a $t_{i+1} ; y_{i+1}=$ incidencia (\%) en $\mathrm{t}_{i+1} ; \mathrm{y}_{i}=$ incidencia $(\%)$ en $\mathrm{t} i$. Los datos se estandarizaron mediante la estimación del ABCPE-absoluta (ABCPEa) (Campbell y Madden, 1990). Para el ABCPEa se realizó un análisis de varianza mediante el procedimiento GLM (SAS Institute, 1999) y comparación de medias mediante la prueba de Tukey $(\mathrm{P} \leq 0.05)$. De los tejidos infectados se reaislaron los hongos y estraminipilas en cultivo puro; las colonias y sus estructuras reproductivas se compararon morfológicamente con las colonias originalmente inoculadas. Este estudio de laboratorio permitió elegir por localidad de estudio, al menos un aislamiento de Fusarium, Rhizoctonia, Macrophomina, Phytophthora y Pythium con los que posteriormente se realizaron las pruebas de patogenicidad en plantas de chile de $45 \mathrm{~d}$ de edad en invernadero; en total se eligieron 15 aislamientos y fueron los que causaron mayor incidencia e intensidad de la enfermedad en plántulas de chile.

\section{Pruebas de patogenicidad en invernadero}

En julio de 2002 , en plantas de chile de 45 d de edad crecidas en condiciones de invernadero, se verificó la patogenicidad de los 15 aislamientos fungosos seleccionados en el laboratorio. Cada aislamiento se consideró un tratamiento, cada uno con 10 repeticiones y la unidad experimental fue una planta de chile. Las plantas se sembraron individualmente en macetas con $2.0 \mathrm{~kg}$ de suelo pasteurizado.

a) Preparación de inóculo. Los inóculos de Macrophomina, Pythium y Rhizoctonia se incrementaron en una mezcla pasteurizada de arena (70 \%), suelo agrícola (29 \%) y harina de maíz (1 \%). Para cada aislamiento se utilizó un frasco de cristal envuelto en papel aluminio con tapa metálica, donde se depositó $1.0 \mathrm{~kg}$ de la mezcla pasteurizada y se agregaron 10 discos miceliales de $0.5 \mathrm{~cm}$ de diámetro del aislamiento correspondiente; los frascos se incubaron a $22 \pm 2{ }^{\circ} \mathrm{C}$ en oscuridad, por $30 \mathrm{~d}$. El inóculo de Fusarium se preparó al cultivar el hongo en PDA a $25{ }^{\circ} \mathrm{C}$ con luz blanca por $5 \mathrm{~d}$. De la colonia se obtuvieron cinco discos miceliales de $1.0 \mathrm{~cm}$ de diámetro, los cuales se transfirieron a $500 \mathrm{~mL}$ de caldo de papa $(100$ $\mathrm{g}$ de papa y $6 \mathrm{~g}$ de dextrosa) y se incubaron en agitación constante a $25{ }^{\circ} \mathrm{C}$ por $5 \mathrm{~d}$ para incrementar la concentración de conidios. Con un hematocitómetro se ajustó la concentración a 1 x $10^{6}$ conidios $\mathrm{mL}^{-1}$. El inóculo de Phytophthora se preparó al cultivar el estraminipila en medio de cultivo V8 $(300 \mathrm{~mL}$ de jugo de verduras V8 Campbell's ${ }^{\circledR}, 4$ g de $\mathrm{CaCO}_{3}$ y $18 \mathrm{~g}$ de agar-agar) a $28{ }^{\circ} \mathrm{C}$ por $5 \mathrm{~d}$, en oscuridad. De la colonia se obtuvieron 10 discos miceliales de $0.5 \mathrm{~cm}$ de diámetro los cuales se depositaron en una caja de Petri con agua destilada estéril y dos hojas de chile previamente hervidas por $5 \mathrm{~min}$, y se incubaron a temperatura ambiente $\left(22 \pm 2{ }^{\circ} \mathrm{C}\right)$ con luz blanca por $96 \mathrm{~h}$; este procedimiento permitió la producción de esporangios los cuales se mantuvieron a $4{ }^{\circ} \mathrm{C}$ por 10 min para que liberaran las zoosporas. Con un hematocitómetro flameado se ajustó la solución a 2000 zoosporas $\mathrm{mL}^{-1}$.

b) Métodos de inoculación. Para inocular Macrophomina, Pythium y Rhizoctonia se usó una espátula estéril con la cual se removió la capa superficial de suelo que cubría las raíces secundarias de cada planta experimental y se mezcló con 100 g del inóculo correspondiente, esta mezcla sirvió para cubrir nuevamente las raíces (Johnson y Carl, 1972). Fusarium y Phytophthora se inocularon mediante el método de inyección conidial y zoospórica, respectivamente, a la rizosfera de las plantas experimentales. En sus tratamientos respectivos, cada planta se inoculó con $10 \mathrm{~mL}$ de solución conidial de Fusarium con una concentración de $1 \times 10^{6}$ conidios $\mathrm{mL}^{-1}$ y con $10 \mathrm{~mL}$ de solución zoospórica a una concentración de 2000 zoosporas $\mathrm{mL}^{-1}$ (Johnson y Carl, 1972). El inóculo de Fusarium y Phytophthora se aplicó a través de dos mangueras de $3.81 \mathrm{~cm}$ de diámetro enterradas a una profundidad de $2.0 \mathrm{~cm}$, con inclinación de $45^{\circ}$ para verter el inóculo en la zona radicular superior de la planta. La incidencia de la enfermedad (plantas marchitas o con muerte total) por tratamiento se evaluó cada $48 \mathrm{~h}$ durante $30 \mathrm{~d}$. La incidencia e intensidad de la enfermedad se estimó con el procedimiento y ecuaciones descritas en la sección de pruebas de patogenicidad in vitro. De los tejidos infectados se reaislaron los hongos y estraminipilas en cultivo puro; las colonias y sus estructuras reproductivas se compararon morfológicamente con las colonias originalmente inoculadas.

\section{Identificación de fitopatógenos}

Los hongos se identificaron mediante las claves taxonómicas para género de Barnett y Hunter (1998). Las especies de Fusarium se identificaron mediante las claves de Booth (1971) y Burgess et al. (1994); para ello se midieron 100 microconidios y 100 macroconidios, se observó tipo de fiálides, y presencia o ausencia de clamidosporas. La especie se corroboró por producción de color en tubos con PDA + pulpa de papa (Nelson et al., 1983) incubados a $25^{\circ} \mathrm{C}$ con luz blanca por $10 \mathrm{~d}$. Las especies de Rhizoctonia se identificaron según las claves de 
Sneh et al. (1991) y por la técnica de safranina "O" (Sneh et al., 1991). Los estraminipilas se identificaron con las claves de Ainsworth et al. (1973) y Watanabe (2002). La especie de Phytophthora se identificó con las claves de Waterhouse (1963) y Erwin y Ribeiro (1996). Los esporangios se produjeron como se describió en la inoculación en invernadero. El tipo de compatibilidad se estudio al aparear en medio de cultivo V8 a aislamientos de Phytophthora capsici tipos A1 y A2 con los aislamientos en estudio. La incubación se hizo a $28{ }^{\circ} \mathrm{C}$ y oscuridad constante durante $10 \mathrm{~d}$.

\section{RESULTADOS Y DISCUSIÓN}

\section{Hongos y estraminipilas aislados}

De 120 plantas con marchitez se obtuvieron 95 aislamientos fungosos de los géneros: Alternaria, Fusarium, Macrophomina, Rhizoctonia, y Stemphylium, los cuales se aislaron de 15, 19, 6, 38 y 17 muestras, respectivamente. Además se obtuvieron ocho y siete aislamientos de Phytophthora y Pythium, respectivamente. En el Cuadro 1 se indica el número de hongos y pseudohongos obtenidos por fecha de muestreo en cada localidad de estudio.

\section{Pruebas de patogenicidad in vitro}

En condiciones de laboratorio, 32 aislamientos mostraron capacidad para causar enfermedad en plántulas de chile de agua; tres fueron de Fusarium, tres de Macrophomina, ocho de Phytophthora, siete de Pythium y once de Rhizoctonia. Las plántulas inoculadas con Fusarium y Macrophomina mostraron síntomas a las $60 \mathrm{y}$ $120 \mathrm{~h}$ después de la inoculación (hdi) respectivamente, y consistieron de cancros en el cuello de raíz con estrangulamiento de $0.5 \mathrm{~cm}$ de longitud, y muerte de plántulas. Phytophthora causó necrosis y muerte de plántulas a las 36 hdi. Pythium y Rhizoctonia indujeron lesiones necróticas en cotiledones y tallo, estrangulamiento y necrosis en el cuello de la raíz con lesiones de $0.5 \mathrm{~cm}$ de longitud y muerte de plántulas a las 48 y 24 hdi, respectivamente. Las plántulas testigo no presentaron síntomas de la enfermedad.

Diversos autores reportan que el ahogamiento de plántulas puede ser causado por Fusarium (Black et al., 1993; Mendoza, 1999), Macrophomina (Dhingra y Sinclair, 1978), Rhizoctonia (Kapoor y Thakur, 1987; Agrios, 2001), Phytophthora (Sarasola y Rocca, 1975; Mendoza, 1999) y Pythium (Iida et al., 1983; Crop Protection Compendium, 2001). Los síntomas de Phytophthora, Pythium y Rhizoctonia coinciden con los reportados por Mendoza (1999). Los síntomas de
Fusarium spp. y Macrophomina spp. fueron similares a los reportados por Black et al. (1993) y Burgess et al. (1994). El análisis de varianza para la variable ABCPEa por localidad de estudio no mostró diferencias significativas $(\mathrm{P} \leq 0.05)$ entre los aislamientos que resultaron patogénicos en condiciones de laboratorio. Iida et al. (1983) y Mendoza (1999) mencionaron a Pythium como el principal agente causante del ahogamiento de plántulas de chile; sin embargo, en este estudio Rhizoctonia mostró mayor agresividad, quizá debido al rápido crecimiento de la colonia en el medio de cultivo $(5 \mathrm{~cm}$ en $60 \mathrm{~h})$. Esta característica permite inferir sobre la habilidad competitiva de $R$. solani en el suelo de los campos de cultivo donde existen plántulas hospedantes y restos vegetales que permiten su supervivencia y diseminación. La temperatura con que se realizaron los ensayos $\left(25 \pm 2{ }^{\circ} \mathrm{C}\right)$ y humedad del sustrato (capacidad de campo) fueron determinantes en la patogenicidad de Rhizoctonia, y estuvieron acordes con las condiciones de campo en los sitios muestreados (25 a $30{ }^{\circ} \mathrm{C}$ en los meses de abril y junio). Esta temperatura en el aire posiblemente permite que el suelo oscile entre $15 \mathrm{y}$ $18{ }^{\circ} \mathrm{C}$, y según Agrios (2001) estas temperaturas son óptimas para que el hongo cause infección y tenga mayor capacidad de propagación.

En la región muestreada los almácigos se cubren con restos vegetales, de modo que la humedad no es excesiva pero se mantiene constante. Agrios (2001) menciona que $R$. solani causa infecciones más severas en suelos moderadamente húmedos que en suelos secos o inundados. En este estudio Macrophomina no expresó su patogenicidad completamente, posiblemente porque no le favoreció la temperatura y la humedad del sustrato. Macrophomina sp. infecta plantas cuyo vigor ha sido reducido por condiciones ambientales desfavorables, como temperaturas de 30 a $35{ }^{\circ} \mathrm{C}$ y humedad aprovechable en el suelo menor a $20 \%$ (o un déficit hídrico de -15 a -20 bar en la planta), que favorecen su agresividad (Dhingra y Sinclair, 1978). Sin embargo, no se descarta la capacidad patogénica de este hongo en campo donde se pueden presentar condiciones ambientales favorables. Los aislamientos de Fusarium, Macrophomina, Rhizoctonia, Phytophthora y Pythium por localidad de estudios que causaron mayor incidencia e intensidad de enfermedad en plántulas de chile de agua se indican en el Cuadro 2; con estos aislamientos se realizaron las pruebas de patogenicidad en plantas de chile de $45 \mathrm{~d}$ de edad en condiciones de invernadero. 
Cuadro1. Hongos y pseudohongos aislados de plantas de chile de agua con síntomas de marchitez muestreadas en tres localidades de los "Valles Centrales" del Estado de Oaxaca, México.

\begin{tabular}{|c|c|c|c|c|c|c|c|}
\hline \multirow[b]{2}{*}{ Género } & \multicolumn{2}{|c|}{$\begin{array}{l}\text { San Jerónimo } \\
\text { Tlacochahuaya }\end{array}$} & \multicolumn{2}{|c|}{ San Sebastián Abasolo } & \multicolumn{2}{|c|}{ Cuilapam de Guerrero } & \multirow[b]{2}{*}{$\mathrm{PP}^{\mathbb{1}(\%)}$} \\
\hline & $2001^{\dagger}$ & 2002 & 2001 & 2002 & 2001 & 2002 & \\
\hline Alternaria spp & $4^{\dagger \dagger}$ & 2 & 3 & 4 & 2 & - & 13.5 \\
\hline Fusarium spp & 3 & 3 & 5 & 2 & 4 & 2 & 17.3 \\
\hline Macrophomina sp & - & - & - & 3 & - & 3 & 5.5 \\
\hline Phytophthora sp & 1 & - & 1 & 3 & 2 & 1 & 7.3 \\
\hline Pythium sp & - & 2 & - & 2 & - & 3 & 6.4 \\
\hline Rhizoctonia spp & 10 & 7 & 7 & 4 & 8 & 2 & 34.6 \\
\hline Stemphylium sp & - & 5 & 2 & 5 & 3 & 2 & 15.4 \\
\hline TAFM $^{\text {q }}$ & 18 & 19 & 18 & 23 & 19 & 13 & \\
\hline
\end{tabular}

Año del muestreo; ${ }^{\dagger}$ Número de aislamientos por género en cada fecha de muestreo; ` Porcentaje de aislamientos por género de las tres localidades de estudio; " Número total de aislamientos por año de muestreo.

Cuadro 2. Aislamientos patogénicos, por localidad de estudio, que causaron mayor incidencia (\%) e intensidad (ABCPEa) de enfermedad (ahogamiento y muerte) en plántulas de chile de agua de $5 \mathrm{~d}$ de edad en condiciones de laboratorio.

\begin{tabular}{|c|c|c|c|c|c|c|}
\hline Localidad & Aislamiento del hongo & $\begin{array}{l}\mathrm{SA}^{\dagger} \\
\text { (hdi) }\end{array}$ & PIA $^{\dagger \dagger}$ & $\begin{array}{l}\mathrm{TA}^{\top} \\
\text { (hdi) }\end{array}$ & $\mathrm{PFA}^{\text {ฯ }}$ & $\mathrm{ABCPEa}^{\xi}$ \\
\hline \multirow{5}{*}{$\begin{array}{l}\text { Cuilapam } \\
\text { de } \\
\text { Guerrero }\end{array}$} & Fusarium & 60 & 30 & 96 & 80 & $0.39 \mathrm{a}$ \\
\hline & Macrophomina & 120 & 20 & 144 & 50 & $0.25 \mathrm{a}$ \\
\hline & Phytophthora & 60 & 10 & 84 & 100 & $0.38 \mathrm{a}$ \\
\hline & Pythium & 48 & 10 & 72 & 100 & $0.54 \mathrm{a}$ \\
\hline & Rhizoctonia & 36 & 10 & 60 & 100 & $0.35 \mathrm{a}$ \\
\hline \multirow{5}{*}{$\begin{array}{c}\text { San } \\
\text { Jerónimo } \\
\text { Tlacochahuaya }\end{array}$} & Fusarium & 60 & 20 & 72 & 100 & $0.42 \mathrm{a}$ \\
\hline & Macrophomina & 130 & 15 & 144 & 50 & $0.33 \mathrm{a}$ \\
\hline & Phytophthora & 48 & 30 & 72 & 100 & $0.53 \mathrm{a}$ \\
\hline & Pythium & 60 & 10 & 84 & 100 & $0.49 \mathrm{a}$ \\
\hline & Rhizoctonia & 24 & 40 & 36 & 100 & $0.47 \mathrm{a}$ \\
\hline \multirow{5}{*}{$\begin{array}{c}\text { San } \\
\text { Sebastián } \\
\text { Abasolo }\end{array}$} & Fusarium & 72 & 20 & 96 & 80 & $0.39 \mathrm{a}$ \\
\hline & Macrophomina & 120 & 10 & 144 & 60 & $0.25 \mathrm{a}$ \\
\hline & Phytophthora & 36 & 10 & 60 & 100 & $0.34 \mathrm{a}$ \\
\hline & Pythium & 48 & 10 & 84 & 100 & $0.35 \mathrm{a}$ \\
\hline & Rhizoctonia & 60 & 30 & 72 & 100 & $0.39 \mathrm{a}$ \\
\hline
\end{tabular}

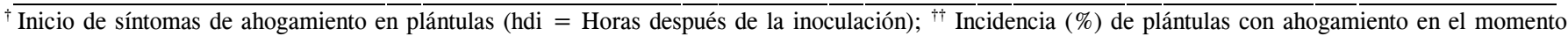
SA; `Evaluación final de incidencia de ahogamiento o muerte total de plántulas (hdi); " Incidencia (\%) de plántulas con ahogamiento o muerte en el momento TA; ${ }^{\zeta}$ Área absoluta bajo la curva del progreso de la enfermedad de plántulas (ahogamiento y muerte). Medias con letras iguales en la columna no son estadísticamente diferentes (Tukey, 0.05).

\section{Pruebas de patogenicidad en invernadero}

De los 15 aislamientos patogénicos en plántulas de chile de agua inoculados en plantas de 45 d de edad, sólo seis indujeron enfermedad. Tres fueron de Phytophthora y tres de Rhizoctonia. Phytophthora causó síntomas de marchitez del follaje en $20 \%$ de las plantas experimentales a los 6 ddi y se observaron lesiones necróticas de aproximadamente $1.0 \mathrm{~cm}$ de longitud en el tejido interno y externo del cuello de la raíz (Figuras 1A, 1B y 1C). En estas plantas algunas hojas se tornaron amarillas y cayeron a los 8 ddi. A los 12 ddi todas las plantas experimentales presentaban marchitez o muerte,(Figura 1A) con lesiones necróticas en el cuello de la raíz de aproximadamente $3.5 \mathrm{~cm}$ de longitud y sin desprendimiento de epidermis (Figura 1B).

Rhizoctonia causó síntomas de marchitez en $20 \%$ de las plantas experimentales a los 34 ddi (Figura 2A); también produjo lesiones necróticas en el cuello de la raíz y tallo, de aproximadamente $1.0 \mathrm{~cm}$ de longitud (Figuras 2B y 2C). La marchitez fue significativa en el día, pero durante la noche el follaje recuperó la turgencia. A los 44 ddi, $80 \%$ de las plantas experimentales mostraron 
marchitez con lesiones necróticas en cuello de raíz de aproximadamente $1.5 \mathrm{~cm}$ de longitud y con desprendimiento de epidermis (Figura 2C). También hubo estrangulamiento, pudrición y desprendimiento de epidermis en raíces secundarias cercanas al cuello de la raíz (Figura 2D), pero las plantas permanecieron vivas. Sólo $20 \%$ de las plantas permanecieron asintomáticas. Las plantas testigo no presentaron síntomas de enfermedad. El análisis de varianza para ABCPEa mostró diferencias significativas $(\mathrm{P} \leq 0.05)$ entre tratamientos de Phytophthora y Rhizoctonia; la intensidad de la enfermedad causada por Phytophthora fue mayor $(\mathrm{ABCPEa}=2.3)$, debido a que infectó a un número mayor de plantas en poco tiempo (12 ddi) respecto a Rhizoctonia que causó enfermedad a los 34 ddi $(\mathrm{ABCPEa}=5.0)($ Figura 3$)$.

Se ha reportado que Phytophthora capsici (Galindo, 1962; Pernezny et al., 2003) y Rhizoctonia solani (Romero, 1994; Pomar et al., 2001) pueden causar marchitez en chile. Los síntomas causados por Phytophthora concuerdan con los reportados por Alcazar et al. (1993), Ristaino y Johnston (1999) y Pernezny et al. (2003). Los síntomas causados por Rhizoctonia coinciden con los reportados por Velásquez et al. (2001) y Romero (1994). En este estudio, la capacidad patogénica de Phytophthora se expresó porque la temperatura prevalente en el suelo donde estuvieron sembradas las plantas de chile fue de 20 a $22{ }^{\circ} \mathrm{C}$, ya que la temperatura mínima para su desarrollo es de $10{ }^{\circ} \mathrm{C}$ y la óptima de $28{ }^{\circ} \mathrm{C}$; además, la humedad del suelo estuvo a capacidad de campo durante esta fase experimental. Estas condiciones fueron favorables para el desarrollo del pseudohongo debido a su naturaleza acuática, ya que ecológicamente el agua libre del suelo y del follaje le favorecen (Erwin y Ribeiro, 1996). Estas condiciones fueron desfavorables para Rhizoctonia debido a que este hongo es activo cuando la temperatura del suelo fluctúa entre 15 y $18{ }^{\circ} \mathrm{C}$ (Romero, 1994; Tlapal, 2000), y aunque la humedad del suelo estuvo a capacidad de campo y con una temperatura de $20-22{ }^{\circ} \mathrm{C}$, el hongo no pudo expresar su virulencia.

Los resultados de este estudio permitirán inferir sobre estrategias de manejo del cultivo, sobre todo en programación y modo de riego para evitar la diseminación del inóculo, particularmente de $P$. capsici (Ristaino y Johnston, 1999). Estos resultados también resaltan la importancia patogénica de Rhizoctonia en las localidades de estudio y que hasta el momento había pasado inadvertida.

\section{Identificación de fitopatógenos}

En plántulas de chile de $5 \mathrm{~d}$ de edad, los aislamientos que causaron enfermedad fueron los hongos: Fusarium lateritium, F. oxysporum, Macrophomina sp., Rhizoctonia sp. (binucleada), $R$. solani y los estraminipilas: Pythium sp., y Phytophthora capsici. En plantas de 45 d de edad causaron enfermedad $R$. solani y Phytophthora capsici.

a) Fusarium lateritium. La colonia en cajas de Petri y tubos con PDA exhibió color rosa pálido y micelio algodonoso; microconidios ausentes; macroconidios fragmosporas hialinos, de tres a cinco septos, con forma de luna y ápices como ganchos de 26.88-33.6 x 3.36-4.48 $\mu \mathrm{m}$, desarrollados en polifiálides; clamidosporas intercalares.

b) $\boldsymbol{F}$. oxysporum. La colonia en cajas de Petri y tubos con PDA exhibió color blanco con pigmentación violeta y micelio algodonoso. Microconidios amerosporas hialinos, elipsoides de 4.97-8.56 x 2.8-3.2 $\mu \mathrm{m}$, no en cadenas, formados en macrofiálides en cabezas falsas en fiálides laterales, simples y cortas. Macroconidios fragmosporas hialinos, de tres a cinco septos, con forma de luna, célula apical ligeramente aguda y célula basal en forma de pie de 30.88-39.56 x 3.87-4.08 $\mu \mathrm{m}$; clamidosporas intercalares. Las características de estos dos aislamientos coincidieron con las reportadas por Booth (1971), Nelson et al. (1983) y Burgess et al. (1994).

c) Rhizoctonia solani. La colonia en PDA fue de color café, micelio fino; conidios ausentes; ramificación hifal a $90^{\circ}$ con constricción hifal; células de 62.72-129.92 x 4.48$6.72 \mu \mathrm{m}$; de seis a ocho núcleos por célula (Figuras 2E2G). Las características de estos dos aislamientos coincidieron con las reportadas por Sneh et al. (1991).

d) Rhizoctonia binucleada. La colonia en PDA fue de color blanco, micelio grueso; conidios ausentes; ramificación hifal a $90^{\circ}$ con constricción hifal; células de 49.28-103.04 x 3.36-4.48 $\mu \mathrm{m}$; dos núcleos por célula.

e) Phytophthora capsici. La colonia en PDA exhibió color blanco, micelio algodonoso formando estrellas; hifas cenocíticas y torulosas; esporangios piriformes con una o dos papilas, de 35.42-48.83 x 25.30-33.88 $\mu \mathrm{m}$; oosporas café, diámetro de 29.16-33.77 $\mu \mathrm{m}$, y grosor de pared de 3.64-4.86 $\mu \mathrm{m}$; anteridio anfígino. $\mathrm{El}$ aislamiento fue heterotálico del tipo A2 (Figuras 1D-1H). Estas características coincidieron con las reportadas por Waterhouse (1963) y Erwin y Ribeiro (1996). 

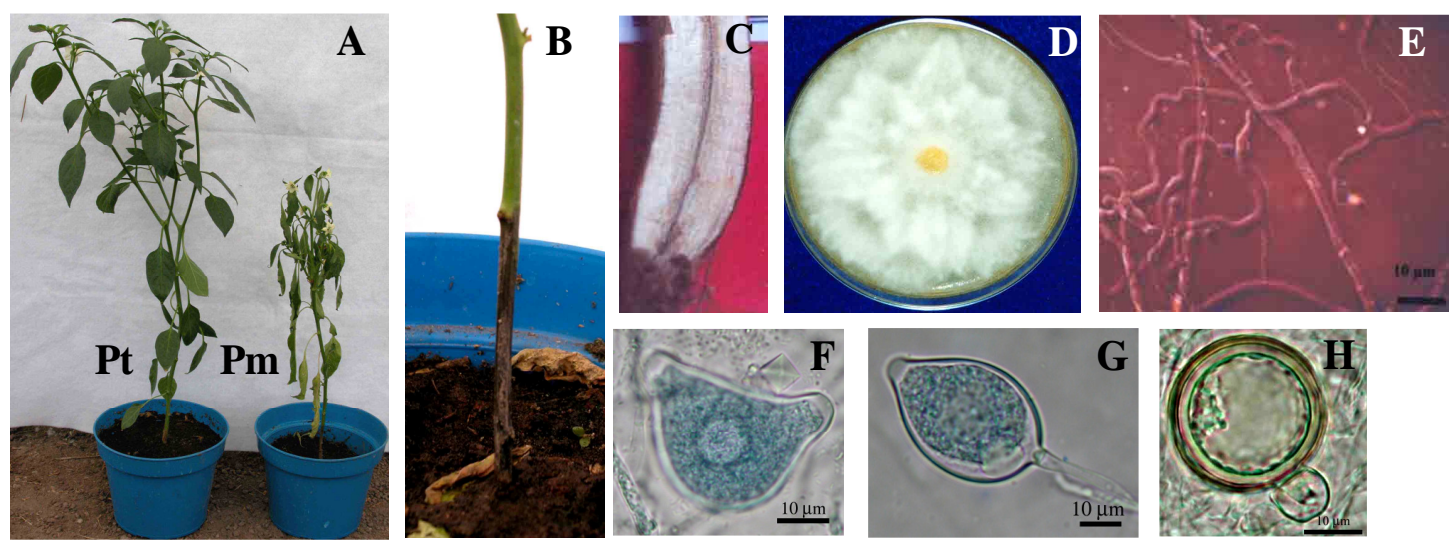

Figura. 1. A-C) Síntomas causados por Phytophthora capsici en plantas de chile de agua (Capsicum annuum) en invernadero. A) Planta testigo (Pt), planta con síntomas de marchitez a 12 d después de inoculada (Pm); B) Tallo con lesión necrótica sin desprendimiento de epidermis; C) Necrosis del tejido interno del tallo; D) Colonia blanca y algodonosa desarrollada por 8 d en papa-dextrosa-agar; E) Hifas cenocíticas (45X); F y G) Esporangios hialinos con dos y una papila (45X); H) Oospora café y anteridio anfígeno hialino (45X).
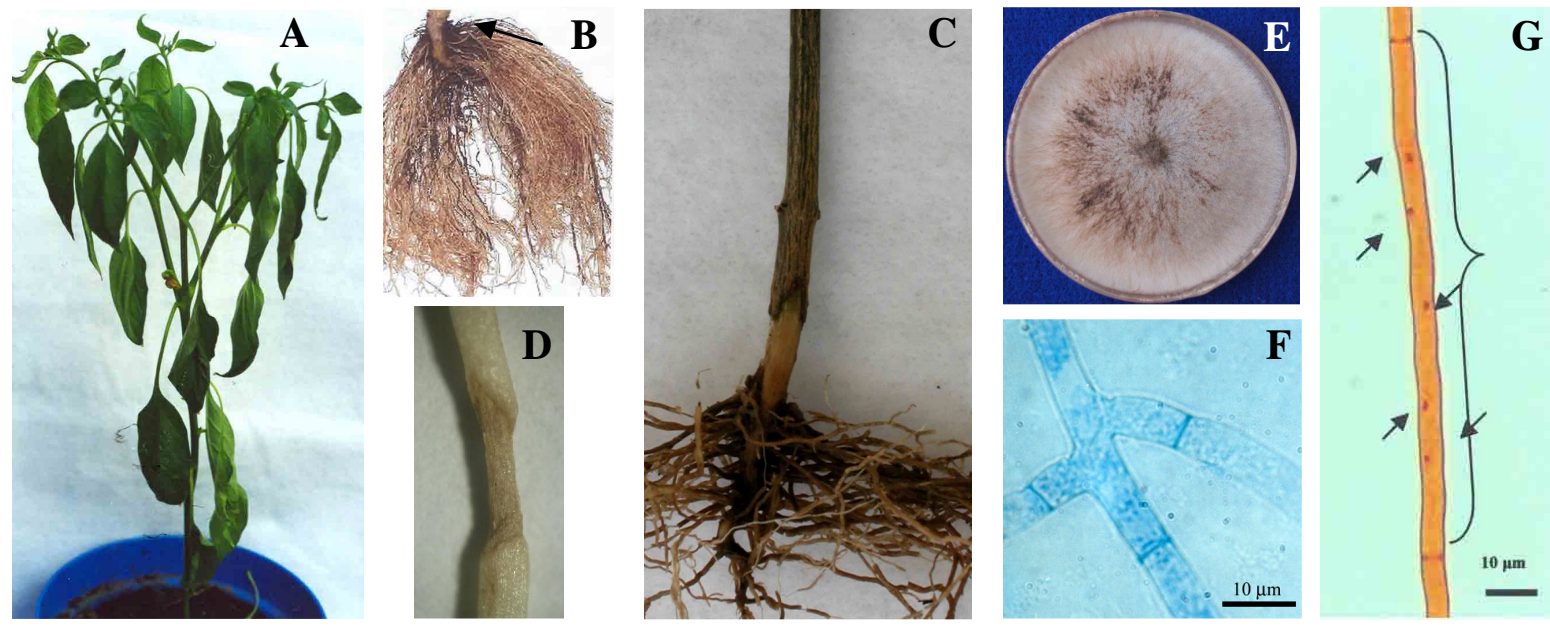

Figura. 2. A-D) Síntomas causados por Rhizoctonia solani (multinucleada) en plantas de chile de agua (Capsicum annuum L.) en invernadero; A) Planta con síntomas de marchitez a 34 d después de inoculada; B) Necrosis de raíz; C) Tallo con lesión necrótica con desprendimiento de epidermis; D) Estrangulamiento y necrosis de raíces secundarias; E) Colonia café en papa-dextrosa-agar de 5 d de edad; F) Ramificación hifal $\left(90^{\circ}\right)$; y G) Célula con cinco núcleos $(45 X)$.

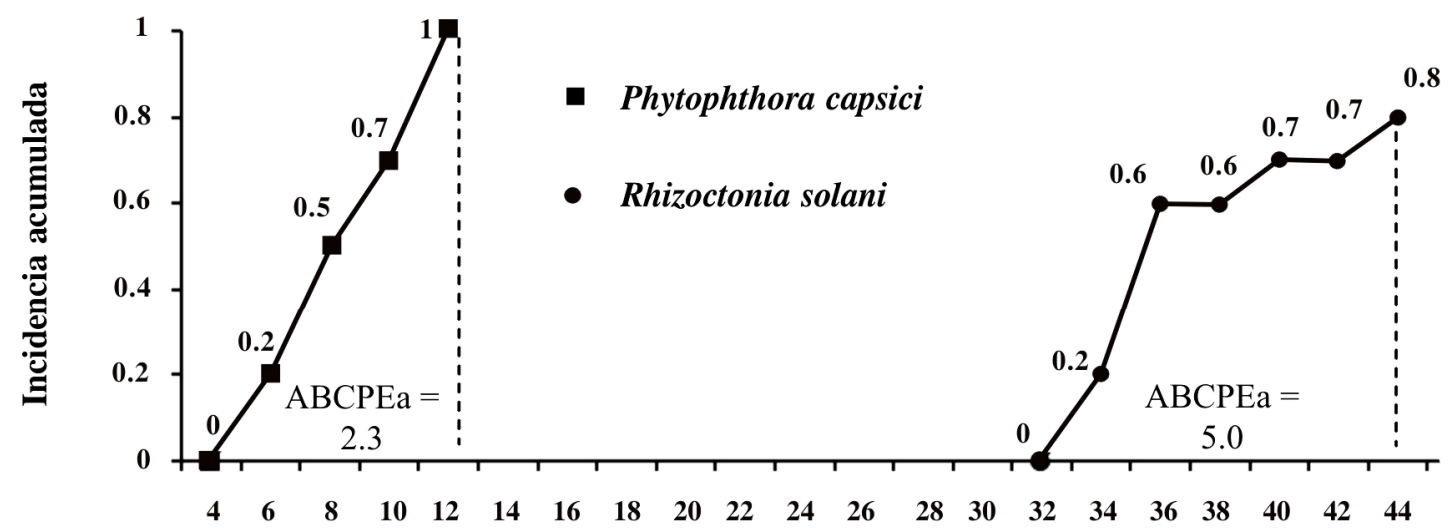

Días después de la inoculación

Figura. 3. Incidencia acumulada e intensidad de la marchitez (área bajo la curva del progreso de la enfermedad) de plantas de chile de agua (Capsicum annuum L.) de 45 d de edad inoculadas con Phytophthora capsici y Rhizoctonia solani en condiciones de invernadero. 


\section{CONCLUSIONES}

Los hongos y estraminipilas que indujeron ahogamiento y muerte de plántulas de chile de agua en condiciones de laboratorio fueron Fusarium lateritium, F. oxysporum, Macrophomina sp., Phytophthora capsici, Pythium sp., Rhizoctonia sp. (binucleada) y $R$. solani.

Rhizoctonia sp. (binucleada) se reporta por primera vez en México como causante de ahogamiento de plántulas de chile.

En este estudio se determinó que Phytophthora capsici y Rhizoctonia solani son los agentes causales de la marchitez y muerte de las plantas de chile de agua (Capsicum annuum L.) en San Jerónimo Tlacochahuaya, San Sebastián Abasolo y Cuilapam de Guerrero, Oaxaca, México. Otros síntomas causados por estos patógenos fueron lesiones necróticas en el cuello de la raíz, estrangulamiento y necrosis de raíces secundarias.

\section{BIBLIOGRAFÍA}

Agrios G N (2001) Fitopatología. Ed. Limusa. México, D.F. 759 p.

Ainsworth C G, F K Sparrow, A S Sussman (1973) The Fungi. An Advanced Treatise. Vol. IVB. A Taxonomic Rewiew with Keys: Basidiomycetes and Lower Fungi. Academic Press. Surrey, UK. $504 \mathrm{p}$.

Alcazar M D, C Egea, A Espín, E Candela (1993) Peroxidasa isoenzymes in the defense response of Capsicum annuum to Phytophthora capsici. Physiol. Plant. 94:736-742.

Barnett L H, B B Hunter (1998) Illustrated Genera of Imperfect Fungi. 4th ed. The American Phytopathological Society. St. Paul, Minnesota, USA. 218 p.

Black L L, K S Green, L G Hartman, M J Poulos (1993) Pepper Diseases: A Field Guide. Asian Vegetable Research and Development Center. Publication No. 91-347. Shanhua, Taiwan. $98 \mathrm{p}$.

Booth C (1971) The genus Fusarium. Commonwealth Mycological Institute. Kew, Surrey, England. 237 p.

Bosland P W, J E Votava (2000) Peppers: Vegetable and Spices Capsicums. Crop Production Science in Horticulture No. 12. CAB International. Las Cruces, New Mexico, USA. 204 p.

Burgess L W, A B Summerell, S Bullock, K P Gott, D Backhouse (1994) Laboratory Manual for Fusarium Research. 3rd ed. Sydney University. Sydney, Australia. 133 p.

Campbell C L, V L Madden (1990) Introduction to Plant Disease Epidemiology. John Wiley and Sons, Inc. New York, USA. 532 p.

Crop Protection Compendium (2001) Global module. Software. 3rd ed. CABI. Wallingford, UK.

Dhingra D O, J B Sinclair (1978) Biology and Pathology of Macrophomina phaseolina. Universidade Federal de Viçosa, Viçosa-Mina Gerais- Brasil. 166 p.

Erwin C D, O K Ribeiro (1996) Phytophthora Diseases Worldwide. The American Phytopathological Society. St. Paul, Minnesota. USA. $562 \mathrm{p}$.
Galindo A J (1962) Marchitez de las plantas de chile causada por Phytophthora capsici Leonian. Rev. Mex. Fitopatol. 1:15-17.

Iida W, K Hirano, Y Amemiya, Y Mita (1983) Influence of soil moisture on the incidence of damping-off of cucumber caused by Fusarium oxysporum f. sp. cucumerinum and Pythium aphanidermatum. Tech. Bull. Fac. Hort. Chiba Univ. 31:81-86.

INEGI (Instituto Nacional de Estadística Geografía e Informática) (2001) Anuario Estadístico del Estado de Oaxaca. Oaxaca, México. 913 p.

Johnson L F, E A Carl (1972) Methods for Research on the Ecology of Soil Borne Plant Pathogens. Burgess Publishing Company. Minneapolis, Minnesota, USA. 247 p.

Kapoor K S, P C Thakur (1987) Control of seed bed losses of Capsicum. Capsicum Newslet. 6:79-80.

Mendoza Z C (1999) Enfermedades fungosas de hortalizas y fresa. In: Hortalizas: Plagas y Enfermedades. S Anaya R, J Romero N (eds). Ed. Trillas. México, D. F. pp:25-63.

Nelson E P, T A Toussoun, W F O Marasas (1983) Fusarium Species. An Illustrated Manual for Identification. The Pennsylvania State University Press. University Park, Pennsylvania, USA. 193 p.

Nuez V F, R O Gil, J G Costa (1996) El Cultivo de Pimientos, Chiles y Ajies. Ed. Mundi-Prensa. Madrid, España. 607 p.

Pernezny K, P D Roberts, J F Murphy, N P Goldberg (2003) Compendium of Pepper Diseases. The American Phytopathological Society. St. Paul, MN, USA. 63 p.

Pomar F, M A Bernal, J Collar, J Díaz, C Caramelo, C Gayoso, M Novo, C Prego, A Saavedra, C Silvar, F Merino (2001) A survey of "tristeza" of pepper in Galicia and the fungal pathogens causing the disease. Capsicum Eggplant Newslet. 20:90-93.

Ristaino J B, S A Johnston (1999) Ecologically based approaches to management of Phytophthora blight on bell pepper. Plant Dis. 83:1080-1089.

Romero C S (1994) Hongos Fitopatógenos. Universidad Autónoma Chapingo. Chapingo, Estado de México, México. 347 p.

Sarasola A A, A M Rocca (1975) Fitopatología. Curso Moderno, Tomo II Micosis. Ed. Hemisferio Sur. Buenos Aires, Argentina. 374 p.

SAS Institute (1999) SAS version 8.0. User's guide: Statistics. Ed. SAS Institute Incorporation, Cary, NC, USA. 1028 p.

Sneh B, L Burpee, A Ogoshi (1991) Identification of Rhizoctonia Species. The American Phytopathological Society. St. Paul, Minnesota, USA. $358 \mathrm{p}$.

Tlapal B B (2000) Características de las enfermedades fungosas en cultivos hortícolas. In: Temas Selectos en Fitosanidad y Producción de Hortalizas. N Bautista M, A D Suárez V, O Morales G (eds). Colegio de Postgraduados, Montecillo, Estado de México, México. pp:106-117.

Velasco V V A, A Trinidad S, J L Tirado T, D Téliz O, A Martínez G, M Cadena H (1998) Efecto de algunos nutrimentos en plantas de chile de agua infectadas con virus. Terra 16:317-324.

Velásquez V R, M M Medina A, J J Luna R (2001) Sintomatología y géneros de patógenos asociados con las pudriciones de la raíz de chile (Capsicum annuum L.) en el Norte-Centro de México. Rev. Mex. Fitopatol. 19:175-181.

Watanabe $\mathbf{T}$ (2002) Pictorial Atlas of Soil and Seed Fungi, Morphologies of Cultured Fungi and Key to Species. 2nd ed. CRC Press. Boca Raton, Florida, USA. 485 p.

Waterhouse G M (1963) Key to the Specie of Phytophthora de Bary. Mycological Papers No. 92. Commonwealth Mycological Institute. Kew, Surrey, England. 22 p.

Zadoks J C, R D Schein (1979) Epidemiology and Plant Disease Management. Oxford University Press. New York, USA. 427 p. 